\title{
ONTOGENETIC STAGES REFLECTED IN CONODONT Pa ELEMENTS: A PROPOSED STANDARDIZED CLASSIFICATION AND ITS PALEOBIOLOGIC IMPLICATIONS
}

\section{LAMBERT, Lance L., Physics Department, Southwest Texas State University, San Marcos, TX 78666-4616}

Lagerstatten specimens of the soft-bodied conodont animal are extremely rare and currently provide no rigorous data to interpret conodont ontogeny. However, the anterior phosphatic histological units that comprised the integrated conodont feeding apparatus are relatively abundant in Paleozoic and Triassic marine strata. Growth series have long been recognized among these intensively studied disjunct skeletal elements, but no widely accepted terminology has been adopted to differentiate ontogenetic categories. Subjective terms such as juvenile, adolescent, and adult pepper the literature--usually without constraint by any state definition, and apparently based on nothing more than relative size. The application of these terms varies significantly from one paper to the next.

Formal definitions have been deterred by the unknown ontogenetic relationship between individual skeletal elements, groups of related elements, and development of the entire conodont animal. Additional complications arise from significant differences in apparatus architecture, reflected in part by conodont taxonomy above the generic level. Different ultimate element sizes for even low-level taxa further confounds potential pro forma designations. Yet for any ontogenetic classification scheme to be useful it must be based on disjunct elements. Further, because most apparatus components are relatively generalized, any categorization should be based on the morphologically distinctive and commonly more robust $\mathrm{Pa}$ elements or their isomorphous equivalents.

The classification system described here relies on the sequence in which diagnostic characters are expressed, in combination with a standardized size distribution within a population framework. Studied growth series indicate that end-members can be reliably employed to impose lower and upper size limits for any given population. The most pronounced early linear character (usually a carina or a cusp) is standardized throughout the growth series as an index. The positive allometry of additional diagnostic characters are then related to that index throughout growth, emphasizing the population mean and mean ultimate size. Thus character development is coupled to a population-based size index as a proxy for relative maturity. This system is adaptable to the diverse morphologies and dimensions exhibited by various higher conodont taxa.

Preliminary results suggest that the growth continuum can be subdivided into five stages common to all conodonts. A formal nomenclature is selected to standardize ontogenetic terminology while freeing the subjective terms for continued informal use. Aside from obvious taxonomic and biostratigraphic implications, this scheme leads to an ability to analyze populations dynamics and mortality, "age"-dependent biofacies distributions, more rigorous study of heterochrony in conodonts, and additional paleobiologic queries. An example of each will be discussed. 